\title{
Analisis Perpindahan Panas Pada Pipa Kalor Bertingkat
}

\author{
Wayan Ainun Wildan Ula ${ }^{1)}$ \\ ${ }^{1)}$ Program Studi Magister Teknik Mesin, Fakultas Teknik, Universitas Udayana \\ JI.P.B. Sudirman Denpasar Bali \\ Email: ainunwildan22@gmail.com
}

doi: https://doi.org/10.24843/METTEK.2019.v05.i02.p02

\begin{abstract}
Abstrak
Perkembangan teknologi Central Processing Unit (CPU) mengarah menuju smart technologies dengan tujuan untuk mendapatkan kinerja yang lebih baik dengan dimensi yang lebih kecil. Namun, hal tersebut menimbulkan permasalahan berupa tingginya fluks kalor yang bisa membuat prosesor rusak. Sehingga, penelitian ini bertujuan untuk merancang pipa kalor lurus bertingkat yang mampu melakukan pendinginan dengan lebih baik tanpa menggunakan energi listrik. Metode yang digunakan dalam penelitian ini adalah dengan pemberian beban kalor pada heat pipe sebesar $10 \mathrm{~W}, 20 \mathrm{~W}, 30 \mathrm{~W}$, dan 40 W. Kemudian dilakukan pengambilan data temperatur dari heat pipe dengan menggunakan NI-DAQ. Lalu, data temperatur tersebut dijadikan dasar dalam perhitungan hambatan termal. Berdasarkan data hasil penelitian dan analisa yang telah dilakukan, didapatkan besarnya hambatan termal pada masing-masing beban kalor secara berurutan adalah $0.97 \mathrm{~K} / \mathrm{W}, 0.69 \mathrm{~K} / \mathrm{W}, 0.65 \mathrm{~K} / \mathrm{W}$, dan $0.79 \mathrm{~K} / \mathrm{W}$.
\end{abstract}

Kata kunci: pipa kalor, hambatan termal, cpu, perpindahan panas

\begin{abstract}
Central Processing Unit (CPU) technologies has led into smart technologies with a purpose to get a better performance followed by a smaller dimensions. However, it makes a significant increase in the heat flux which has a potential to break the processor. So in this research, cascade straight heat pipe was designed to get a better cooling performance without electrical energy supplies. The methods used in this research are by giving the heat pipe some heat loads in amount of $10 \mathrm{~W}, 20 \mathrm{~W}, 30 \mathrm{~W}$, and $40 \mathrm{~W}$, respectively. And then, the temperature data of the heat pipe was recorded by using NI$D A Q$. Finally, the temperature data was used as the main data to calculate the thermal resistance analysis. Based on the result of the research and the analysis that has been done before, thermal resistance for each heat loads has been acquired, they are 0.97 $\mathrm{K} / \mathrm{W}, 0.69 \mathrm{~K} / \mathrm{W}, 0.65 \mathrm{~K} / \mathrm{W}$, and $0.79 \mathrm{~K} / \mathrm{W}$, respectively.
\end{abstract}

Keywords: heat pipe, thermal resistance, cpu, heat transfer

\section{PENDAHULUAN}

Seiring dengan perkembangan zaman dan kebutuhan manusia akan hal yang praktis, teknologi yang membantu pekerjaan manusia juga mampu bekerja dengan semakin baik dan pintar. Salah satu teknologi yang mengalami kemajuan cukup pesat adalah komputer. Adapun bagian terpenting dari sebuah komputer adalah processing unit-nya (CPU).

Central Processing Unit (CPU) mengalami perkembangan yang sangat pesat [1]. Perkembangan dari CPU mengarah menuju smart technology yang menuntut dimensi lebih kecil namun dengan kinerja yang lebih baik [2]. Tuntutan dari smart technology ini berakibat pada tingginya kalor yang harus dibuang dari CPU untuk menjaga kinerjanya dan

Penulis korespondensi

Email: ainunwildan22@gmail.com 
menghindari terjadinya kerusakan yang bersifat permanen. Untuk mengatasi masalah pembuangan kalor tersebut, maka CPU membutuhkan sistem pendingin yang memiliki kinerja tinggi, dimensi kecil, namun tidak membutuhkan energi listrik [3], [4].

Sehingga, dilihat dari sifat-sifat pendingin yang dibutuhkan, heat pipe bisa dijadikan sebagai solusi alternatif bagi permasalahan pendingin yang ada, terkait dengan prinsip kerja heat pipe yang menerapkan konsep pendinginan pasif dan mampu menyerap kalor lebih baik dibandingkan metode yang telah ada sebelumnya. Heat pipe merupakan teknologi bantu perpindahan kalor dengan menggunakan pipa dengan wick dan fluida kerja di dalam pipa yang mampu memindahkan kalor dari bagian evaporator menuju bagian kondensor. Performa dari heat pipe dipengaruhi oleh beberapa indikator, seperti beban kalor, tipe material, porositas dan permeabilitas wick, jenis dan jumlah fluida kerja dan bentuk dari heat pipe yang digunakan.[5].

Sebelumnya, telah dilakukan berbagai penelitian mengenai penggunaan heat pipe untuk mengatasi masalah manajemen kalor pada sistem CPU, adapun beberapa diantaranya adalah penggunaan heat pipe sebagai sistem pendingin dengan wick biomaterial [6]-[8] dan penggunaan sistem pendingin dengan pengintegrasian sintered powder dan screen mesh wick [5], [9]-[12].

Kemampuan heat pipe yang sangat baik dalam memindahkan kalor, menyebabkan tingginya temperatur kalor buangan pada kondensor [9], [10], [12]. Tingginya kalor buangan pada kondensor, menyatakan bahwa pengembangan teknologi heat pipe belum mencapai potensi maksimalnya. Karena, kalor buangan tersebut masih berpotensi untuk merusak komponen hardware dari komputer, sehingga harus cepat dibuang. Dan solusi untuk mempercepat pembuangan kalor ini adalah dengan penggunaan kipas yang membutuhkan tenaga listrik. Sehingga, tujuan awal penggunaan heat pipe sebagai pendingin pasif belum tercapai.

Jadi, agar bisa mencapai tujuan awal penggunaan heat pipe sebagai alat pendinginan pasif, penulis memutuskan untuk melakukan penelitian mengenai penggunaan cascade straight heat pipe sebagai sistem pendingin pada CPU. Cascade straight heat pipe terdiri dari dua evaporator, dua kondensor, dan daerah adiabatis. Dengan penggunaan cascade straight heat pipe, maka kalor dari komputer yang diserap melalui bagian evaporator di tingkat I, tidak langsung dilepas ke lingkungan. Melainkan disalurkan terlebih dahulu ke evaporator heat pipe tingkat II dan akhirnya dibuang melalui kondensor tingkat II. Yang mana secara teoritis tentunya temperatur kalor buangnya akan semakin kecil, sehingga penggunaan tenaga listrik untuk kipas tidak lagi dibutuhkan.

Dengan membuat pipa kalor bertingkat, maka tentunya hambatan termal akan mengalami peningkatan. Namun, peningkatan yang terlalu signifikan dan mengganggu terjadi proses perpindahan panas tentu tidak diinginkan, oleh karena itu besarnya hambatan termal dari pipa kalor lurus bertingkat perlu untuk dianalisis, agar kita dapat mengetahui apakah pipa kalor bekerja dengan baik atau tidak.

Penelitian ini, akan menganalisa besarnya hambatan termal pada heat pipe melalui pengambilan data temperatur di evaporator tingkat I dan II, kondensor tingkat I dan II, dan daerah sambungan antara kedua heat pipe tersebut, untuk kemudian dilakukan analisa dari hambatan termal pada cascade straight heat pipe melalui perhitungan. Adapun hasil penelitian yang diharapkan adalah output temperatur dari kondensor nilainya $<60^{\circ} \mathrm{C}$ dan hambatan termal heatpipe yang kecil [13]

Sedangkan, pipa kalor bertingkat merupakan gabungan dari 2 pipa kalor (tingkat I dan II) yang disambungkan pada bagian kondensor dan evaporator yang mana dianggap sebagai kondensor I dan evaporator II. Prinsip kerja dasar pipa kalor bertingkat sendiri serupa dengan pipa kalor tunggal yang dipaparkan sebelumnya, hanya saja setelah panas dibuang melalui kondensor pipa kalor tingkat I, panas tidak langsung mengalir ke lingkungan, namun diserap 
kembali oleh evaporator pada pipa kalor tingkat II, sehingga proses pendinginan terjadi dalam dua tahapan, dan temperatur buangan pada kondensor pipa kalor tingkat II menjadi lebih kecil dibandingkan temperatur buangan pada kondensor pipa kalor tunggal [14].

\section{METODE}

Dalam penentuan kinerja heat pipe, hambatan termal merupakan salah satu faktor yang dianggap penting. Dimana, jika heat pipe memiliki hambatan termal yang kecil, maka kinerja termal dari heat pipe tersebut dianggap baik, dan berlaku juga sebaliknya jika hambatan termal dari heat pipe tersebut besar. Oleh karena itu, penulis melakukan penelitian untuk mengetahui besarnya hambatan termal dari cascade straight heat pipe untuk mengetahui apakah jenis heat pipe ini layak untuk diaplikasikan sebagai pendingin processing unit.

Variasi beban daya yang diberikan pada heatpipe sekitar $10 \mathrm{~W}$ hingga $40 \mathrm{~W}$. Rentang variasi yang digunakan mengacu pada karakterisasi yang telah dilakukan terhadap miniCPU core i5 $3.30 \mathrm{GHz}$. Karakterisasi ini dilakukan dengan metode thermal imaging terhadap permukaan prosesor pada kondisi idle dan kondisi operasi maksimum. Ditemukan bahwa temperatur prosesor saat kondisi idle dan operasi maksimum yaitu $78.27{ }^{0} \mathrm{C}$ dan $110.39{ }^{0} \mathrm{C}$. Kondisi idle dan operasi maksimum pada prosesor, sebanding dengan pemberian daya $10 \mathrm{~W}$ dan $40 \mathrm{~W}$.

Skematik pengujian dari cascade straight heat pipe ditampilkan pada Gambar 1 Penelitian ini dilakukan menggunakan dua heat pipe jenis L yang digabungkan untuk membentuk cascade straight heat pipe. Seluruh bagian dari heatpipe kecuali evaporator tingkat I dan kondensor tingkat II diisolasi menggunakan isolator polyurethane, yang bertujuan untuk meminimalisir pengaruh panas dari lingkungan dan keluarnya panas yang berlebih dari heatpipe.

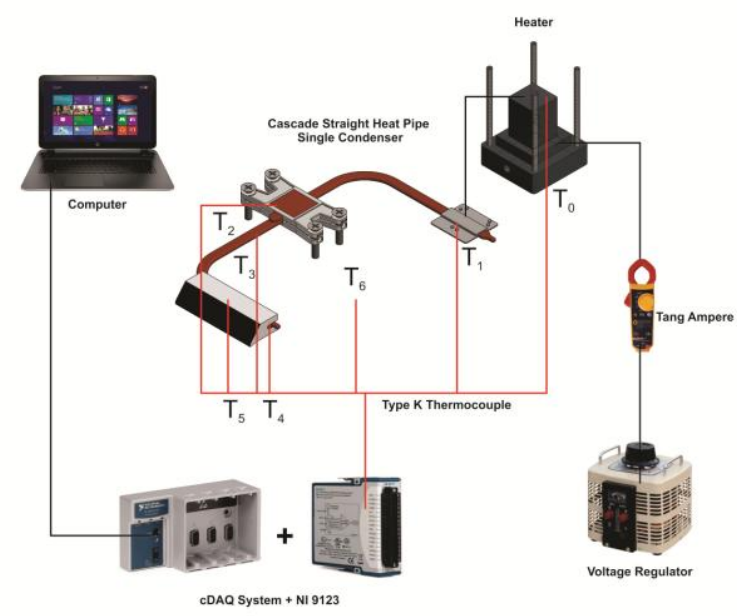

Gambar 1. Skematik pengujian pipa kalor lurus bertingkat

Pengujian dilakukan menggunakan pelat pemanas berbahan aluminium sebagai simulator prosesor yang menjadi sumber kalor. Beban kalor yang dihasilkan oleh pelat simulator diatur melalui voltase yang diberikan oleh voltage regulator. Lalu, 11 termokopel tipe $\mathrm{K}$ dipasangkan ke 11 titik pengukuran temperatur yaitu pelat simulator, bagian evaporator 1 , fluida evaporator 1, kondensor 1, fluida kondensor 1, evaporator 2, fluida evaporator 2, kondensor 2, fluida kondensor 2, heatsink, dan lingkungan sekitar.

Setelah semua termokopel terpasang di titik pengukuran, ketujuh termokopel disambungkan ke modul NI-9123 + cDAQ-9174 yang sudah terhubung ke komputer dengan software Natural Instruments (NI), sehingga perubahan temperatur pada heat pipe bisa diamati. Adapun setelah data temperatur steady didapatkan, maka besarnya hambatan termal 
bisa dihitung menggunakan persamaan (1).

$$
R_{h p c}=\frac{T_{e I}-T_{c I I}}{\dot{Q}}
$$

\section{HASIL DAN PEMBAHASAN}

Berdasarkan pengujian yang telah dilaksanakan, didapatkan data berupa distribusi temperatur pada masing-masing pembebanan. Adapun data untuk temperatur evaporator I dan kondensor II secara lengkap ditampilkan pada Tabel 1.

Tabel 1. Data distribusi temperatur evaporator I dan kondensor II pada masing-masing beban kalor

\begin{tabular}{ccc}
\hline Beban Kalor $(\mathrm{W})$ & $\mathrm{T}_{\text {evaporatorI }}(\mathrm{K})$ & $\mathrm{T}_{\text {kondensorII }}(\mathrm{K})$ \\
\hline 10 & 309.18 & 299.51 \\
20 & 313.80 & 299.98 \\
30 & 322.93 & 303.40 \\
40 & 335.33 & 303.87 \\
\hline
\end{tabular}

Setelah besarnya temperatur pada evaporator I dan II diketahui, maka besarnya hambatan termal bisa dihitung menggunakan persamaan (1). Setelah dilakukan perhitungan hambatan termal untuk masing-masing beban kalor. Maka, didapatkan hasil perhitungan seperti yang ditampilkan pada Gambar 2.

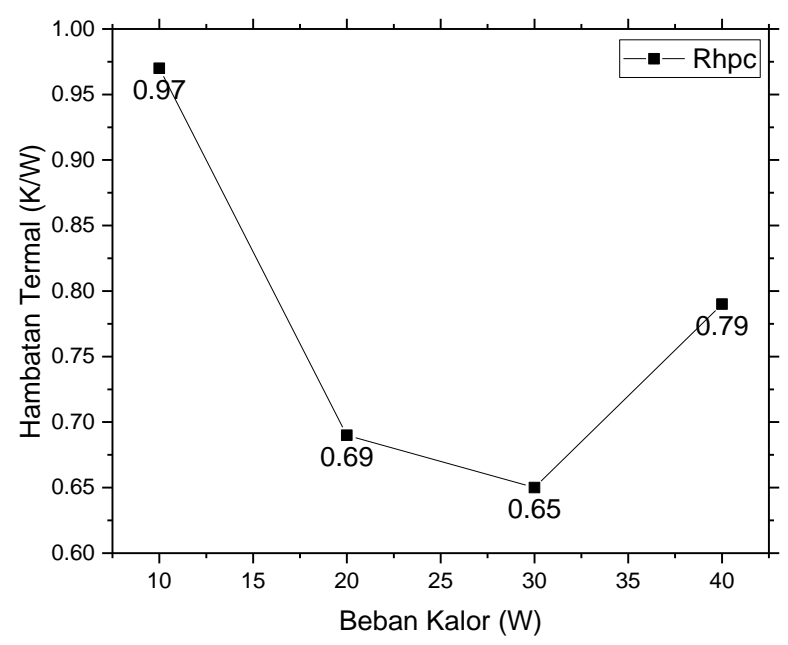

Gambar 2. Grafik hambatan termal terhadap beban kalor

Pada gambar 2, bisa dilihat nilai hambatan termal pada beban kalor $10 \mathrm{~W}$ besarnya 0.97 $\mathrm{K} / \mathrm{W}$, lalu nilai hambatan termal pada beban kalor $20 \mathrm{~W}$ mengalami penurunan yang cukup besar sehingga menjadi $0.69 \mathrm{~K} / \mathrm{W}$, pada beban kalor $30 \mathrm{~W}$, nilai hambatan termal kembali mengalami penurunan meskipun tidak terlalu signifikan, menjadi $0.65 \mathrm{~K} / \mathrm{W}$, dan pada beban kalor $40 \mathrm{~W}$, hambatan termal mengalami peningkatan menjadi $0.79 \mathrm{~K} / \mathrm{W}$.

Jika kita memperhatikan pada Gambar 3, bisa dilihat bahwa hambatan termal tertinggi berada pada beban kalor $10 \mathrm{~W}$, jika kita perhatikan kembali pada Tabel 1, temperatur evaporator pada beban kalor $10 \mathrm{~W}$ besarnya $309.18 \mathrm{~K}$ atau setara dengan $36.18{ }^{\circ} \mathrm{C}$. Sehingga, fluida kerja pipa kalor baik pada tingkat I dan II belum mengalami evaporasi sepenuhnya. 
Sehingga, proses perpindahan panas tidak berjalan dengan baik dan menimbulkan nilai hambatan termal yang besar.

\section{SIMPULAN}

Berdasarkan penelitian dan analisis yang telah dilakukan sebelumnya, adapun besarnya hambatan termal pada beban kalor $10 \mathrm{~W}, 20 \mathrm{~W}, 30 \mathrm{~W}$, dan $40 \mathrm{~W}$ secara berurutan nilainya $0.97 \mathrm{~K} / \mathrm{W}, 0.69 \mathrm{~K} / \mathrm{W}, 0.65 \mathrm{~K} / \mathrm{W}$, dan $0.79 \mathrm{~K} / \mathrm{W}$. Hambatan termal cenderung mengalami penurunan seiring dengan peningkatan beban kalor yang diterima, namun pada beban kalor 40 $\mathrm{W}$, hambatan termal mengalami peningkatan akibat terbentuknya nukleat yang menghambat proses perpindahan panas.

\section{DAFTAR PUSTAKA}

[1] K. V Paiva and M. B. H. Mantelli, "Wire-plate and sintered hybrid heat pipes: Model and experiments," Int. J. Therm. Sci., vol. 93, pp. 36-51, 2015.

[2] Q. Chen and Y. Huang, "Scale effects on evaporative heat transfer in carbon nanotube wick in heat pipes," Int. J. Heat Mass Transf., vol. 111, pp. 852-859, 2017.

[3] D. Liu, F.-Y. Zhao, H.-X. Yang, and G.-F. Tang, "Thermoelectric mini cooler coupled with micro thermosiphon for CPU cooling system," Energy, vol. 83, pp. 29-36, 2015.

[4] S. Wang, J. Chen, Y. Hu, and W. Zhang, "Effect of evaporation section and condensation section length on thermal performance of flat plate heat pipe," Appl. Therm. Eng., vol. 31, no. 14, pp. 2367-2373, 2011.

[5] N. Putra, W. N. Septiadi, and R. Irwansyah, "Effect of Concentration and Loading Fluid of Nanofluids on the Thermal Resistance of Sintered Powder Wick Heat Pipe," Adv. Mater. Res., vol. 651, pp. 728-735, Jan. 2013.

[6] N. Putra, R. Saleh, W. N. Septiadi, A. Okta, and Z. Hamid, "Thermal performance of biomaterial wick loop heat pipes with water-base $\mathrm{A} 12 \mathrm{O} 3$ nanofluids," Int. J. Therm. Sci., vol. 76, pp. 128-136, Feb. 2014.

[7] N. Putra, W. N. Septiadi, R. Saleh, R. A. Koestoer, and S. Purbo Prakoso, "The Effect of CuO-Water Nanofluid and Biomaterial Wick on Loop Heat Pipe Performance," $A d v$. Mater. Res., vol. 875-877, pp. 356-361, Feb. 2014.

[8] N. Putra and W. N. Septiadi, "Improvement of heat pipe performance through integration of a coral biomaterial wick structure into the heat pipe of a CPU cooling system," Heat Mass Transf., vol. 53, no. 4, pp. 1163-1174, Apr. 2017.

[9] W. N. Septiadi, N. Putra, M. Juarsa, I. P. . Putra, R. Sahmura, and R. Sahmura, "Characteristics of Screen Mesh Wick Heat Pipe with Nano-fluid as Passive Cooling System," Atom Indones., vol. 39, no. 1, p. 24, Jun. 2013.

[10] N. Putra, Saputra, M. I. Bimo, R. Irwansyah, and S. N. Wayan, "Experimental study on sintered powder wick loop heat pipe," 2012, pp. 612-620.

[11] N. Putra, W. N. Septiadi, R. Sahmura, and C. T. Anggara, "Application of Al2O3 nanofluid on sintered copper-powder vapor chamber for electronic cooling," in Advanced Materials Research, 2013, vol. 789, pp. 423-428.

[12] N. Putra, W. N. Septiadi, H. Rahman, and R. Irwansyah, "Thermal performance of screen mesh wick heat pipes with nanofluids," Exp. Therm. Fluid Sci., vol. 40, pp. 1017, Jul. 2012.

[13] N. Putra and W. N. Septiadi, Teknologi Pipa Kalor Teori, Desain, dan Aplikasi. Jakarta: Universitas Indonesia, 2014.

[14] N. Putra, A. Duanovsah, and K. Haliansyah, "Investigation of Cascade Loop Heat Pipes," Int. J. Mech. Aerospace, Ind. Mechatron. Manuf. Eng. Vol9, vol. 9, no. 10, pp. 1868-1872, 2015. 